\title{
Profiles of discontinuation and switching of thiazide diuretics: a cohort study among 9398 Chinese hypertensive patients
}

\author{
Martin CS Wong ${ }^{1}$, Xuefen Su${ }^{1}$, Johnny Y Jiang ${ }^{2}$, Jin-Ling Tang ${ }^{1}$ and Sian M Griffiths ${ }^{1}$
}

This study tested the hypothesis that younger, male patients or new clinic visitors, who were prescribed thiazide diuretics were more likely to have drug discontinuation and switching. All adult patients who visited any primary care clinic in one territory of Hong Kong, and who were prescribed a thiazide diuretic from January 2004 to June 2007 were included. The rates of discontinuation and switching, separately, 180 days after thiazide prescriptions were measured. Factors associated with discontinuation and switching were evaluated by multiple regression analyses. Among 9398 patients, $12.5 \%$ discontinued and $10.8 \%$ switched their prescriptions, whereas prescriptions of other patients remained the same. Younger patients $(<50$ years (reference value); adjusted odds ratio (AOR) for $50-59$ years $=0.74,95 \%$ confidence interval (CI) $0.61-0.90, P=0.002$; AOR (60-69 years) $=0.57,95 \% \mathrm{Cl} 0.46-0.70, P<0.001 ;$ AOR ( $\geqslant 70$ years) $=0.88,95 \% \mathrm{Cl} 0.73-1.06, P=0.174$ ), male subjects $(A O R=1.23,95 \% \mathrm{Cl} 1.07-1.40, P=0.003$ ) and new visitors (AOR (repeat visitors) $=0.55,95 \% \mathrm{Cl} 0.47-0.65, P<0.001$ ) were more likely to be discontinuers. These associations between younger age ( $<50$ years (reference value); AOR (50-59) years $=0.85,95 \% \mathrm{Cl} 0.70-1.04, P=0.112$; AOR $(60-69$ year $)=0.79,95 \% \mathrm{Cl} 0.65-0.98, P=0.028 ; A O R$ ( $\geqslant 70$ years $)=0.70$, $95 \% \mathrm{Cl} 0.57-0.85, P<0.001$ ), male gender (AOR=1.29, 95\% Cl 1.12-1.48, $P<0.001$ ) and new visitors (AOR (repeat visitors) $=0.57,95 \% \mathrm{Cl} 0.48-0.67, P<0.001$ ) were also significant for medication switching. Clinicians should monitor the medication-taking behavior more closely among patients aged 50-59 years, male subjects and new clinic visitors when thiazide was prescribed.

Hypertension Research (2011) 34, 888-893; doi:10.1038/hr.2011.43; published online 12 May 2011

Keywords: associated factors; Chinese; discontinuation; switching; thiazide diuretic

\section{INTRODUCTION}

Thiazide diuretics have been recommended by major international guidelines as a suitable first-line antihypertensive agent for the management of arterial hypertension. ${ }^{1-4}$ It was suggested by the European Society of Hypertension/European Society of Cardiology $(\mathrm{ESH} / \mathrm{ESC})^{2}$ and the World Health Organization/International Society of Hypertension (WHO/ISH) guidelines ${ }^{3}$ as one of the major options of drug choice. The Antihypertensive and Lipid-Lowering Treatment to Prevent Heart Attack Trial (ALLHAT), ${ }^{5}$ for instance, has provided evidence that diuretics had similar protection against fatal and nonfatal cardiovascular diseases, as compared with angiotensin-converting enzyme inhibitors and calcium channel blockers. In addition, the seventh report of the Joint National Committee suggested that all stage 2 hypertensive patients (systolic blood pressure (SBP) $\geqslant 160 \mathrm{~mm} \mathrm{Hg}$ or diastolic blood pressure (DBP) $\geqslant 100 \mathrm{~mm} \mathrm{Hg}$ ) should be started on two-drug combinations, one of which should be a thiazide diuretic. ${ }^{4}$
In addition, thiazide has been reported as one of the most popular antihypertensive prescriptions in Ontario ${ }^{6}$ and the UK. ${ }^{7}$ In the US, a nation-wide study has shown that thiazide was the most commonly prescribed drug class consisting of approximately half of all antihypertensive prescriptions, and its use was still on the rise. ${ }^{8}$ Among all the antihypertensive drug classes dispensed in the public sector of a large territory of Hong Kong from 2004 to 2007, up to $12-14 \%$ of prescriptions consist of a thiazide diuretic. ${ }^{9}$ This antihypertensive drug class, therefore, remained an important pharmacotherapy in the management of hypertension in clinical practice.

A recent study conducted in two public primary care clinics in Hong Kong showed that thiazide had low discontinuation rates in the short ( 8 weeks) and long (48 weeks) term. ${ }^{10}$ Our recent published studies in a larger cohort of Chinese hypertensive patients, who were prescribed any antihypertensive drug classes, showed that younger, male subjects or new clinic visitors were more likely to discontinue or

${ }^{1}$ School of Public Health and Primary Care, Faculty of Medicine, Chinese University of Hong Kong, Hong Kong, China and ${ }^{2}$ Chinese Academy of Medical Science and Peking Union Medical College, Beijing, China

Prior Presentations: The abstract of this study has been presented in the European Society of Cardiology Congress, 2010

Correspondence: Dr JY Jiang, Chinese Academy of Medical Sciences and Peking Union Medical College, DongDan SanTiao 9, DongCheng District, Beijing 100730, China. E-mail: wingedsky@gmail.com

Received 26 October 2010; revised 19 February 2011; accepted 21 February 2011; published online 12 May 2011 
change antihypertensive regimen. ${ }^{9,11,13}$ However, when patients, who were prescribed calcium channel blockers were analyzed separately, ${ }^{14}$ male and female subjects were equally likely to have their prescriptions discontinued. Given the different side-effect profiles of various antihypertensive drugs, this could have significant variations among the factors associated with their discontinuation and switching. Thus, far among hypertensive patients who were prescribed thiazide diuretics, it is unknown who are more likely to be discontinuers or switchers.

The objective of this study is to evaluate the factors associated with thiazide discontinuation and switching among ethnic Chinese patients in a primary care setting. The present study tested the hypothesis that young patient, male subjects and first-time clinic visitors who received their first-ever thiazide diuretic were significantly associated with discontinuation and switching of thiazide prescriptions.

\section{METHODS}

\section{Data source}

The database used in this study has also been described elsewhere. ${ }^{11,13,15}$ Briefly, the hospital authority of Hong Kong offers free or low cost primary and secondary care as part of the public health care sector. This study utilized the Clinical Data Analysis Reporting System (CDARS) of the Hospital Authority, containing patients' clinical and demographic parameters, clinical diagnoses in terms of International Classification of Primary Care (ICPC) codes, types of clinical services (General Outpatient Clinic (GOPC) vs. Family Medicine Specialist Clinic (FMSC) vs. staff clinics), as well as drug prescription details. GOPCs mainly provide first-contact primary care services to all residents in Hong Kong. Patients with more complicated medical conditions requiring further specialist assessment and management will be seen in FMSCs after referrals from primary care physicians. Staff clinics offer free-of-charge medical services to staff employed by the hospital authority. Research is one of the functions of CDARS, ${ }^{16}$ and previous evaluations on this database showed that the demographic details and prescription information were complete. ${ }^{15}$ Some attributes of this database enhance research. ${ }^{15}$ For every clinic visit, patients must register at first visit with their formal identity documents and their sociodemographic data are entered into the computer system by administrative staff. Attending physicians must enter all prescriptions into the computer system, which will then be checked by the dispensary office. Each prescription involves at least two independent pharmacy professionals to ensure accurate drug dispensing. Prescription orders, including self-financed items, can only be issued by the computer. All amendments to drug prescription orders by physicians after the consultations will also be captured and updated by the computer system. These computerized clinical records are the only routes of information entry by physicians for every consultation in all primary care clinics run by the hospital authority. They are comprehensive, allowing crossreferencing by physicians, when patients attend a different clinic in the same or different regions in the public sector. There are clinical guidelines indicating that every physician should enter the diagnosis in the form of ICPC codes upon completion of each consultation.

The data sources in this study include patient information from the New Territory East region of Hong Kong which offers primary healthcare services to around 1.3 million residents, that is, $17.2 \%$ of the Hong Kong population. ${ }^{17}$ The New Territory East region is further divided into three separate geographical regions, namely Shatin (most urbanized), Taipo and North district (most rural). The median monthly household income in 2006 were equivalent to US $\$ 2510$, US\$2338 and US\$2078 for these three regions, respectively, and were comparable to the Hong Kong-wide figure of US\$2240. ${ }^{17}$ These three regions have similar median ages (38-39 years) comparable to the median age of 39 years for the Hong Kong population. This study was approved by the Survey and Research Behavioural Ethics Committee, Faculty of Medicine, Chinese University of Hong Kong. We anonymized all patients and replaced each patient's name by a unique identifier.

\section{Study cohort}

All adult patients who visited any primary care clinic, at least once and were prescribed a thiazide diuretic in the period January 2004 to June 2007 were included. Patients who were already and newly prescribed thiazide diuretics were both included as we aimed to explore differences in discontinuation and switching of medications between these two groups. Patients who died after they received their thiazide prescription, but before the next scheduled visit for thiazide drug refill were excluded. Each patient was represented only once taking into account the first visit as the index date. We assigned each patient with different numbers of comorbidities, according to the ICPC coding. Comorbidities refer to any concomitant cardiovascular risk factors (for example, diabetes mellitus, dyslipidemia), medical conditions confounding the choice of antihypertensive agents (for example, chronic obstructive airway diseases, renal problems), and the compeling indications or contraindications of a particular antihypertensive drug class (for example, heart disease, gout). A complete list of these conditions was presented elsewhere. ${ }^{11}$ Variables tested for association included patients' age, gender, and the visit type (new $v s$. follow-up visits). Payment status (fee-waivers vs. payers), service types (GOPC vs. FMSC vs staff clinic), district of residence, the number of comorbidities and the calendar years of prescriptions were used as covariates. To qualify for feewaiving, which applies to all clinical services and medication costs, a patient should undergo a comprehensive assessment by a social worker for their inability to pay. This is used as a proxy measure of socioeconomic status in the present study.

\section{Outcome measures}

The primary outcome measures were the 180-day cumulative incidences of drug discontinuation and switching, separately. Drug discontinuation was defined as the absence of a refill prescription in all subsequent clinic visits, without issuance of another antihypertensive drug within the time frame of 180 days, since the first prescription date. Drug switching was defined as replacement of the thiazide prescription by another antihypertensive medication in the same time frame. Previous studies on antihypertensive drug discontinuation in the $\mathrm{UK}^{18}$ and Italy ${ }^{19}$ used 90 days as the reference. We adopted a 180-day observation period for this study, taking into account the practice of prescribing antihypertensive drugs ranging from 14 to 168 days (median 56 days) in our clinical database.

\section{Statistical analyses}

We measured the cumulative incidences of thiazide discontinuation and switching, and compared the sociodemographic information of the discontinuers and switchers $v s$. those who had not discontinued and not switched, respectively, using $\chi^{2}$-tests. We conducted two separate, unconditional binary logistic regression equations, with drug discontinuation and switching as outcome variables, separately. All predictor variables described above were entered into the regression models. We checked for the absence of multicollinearity $(r>0.80)$ among all the predictor variables. ${ }^{20}$ As part of sensitivity analyses, we extended the period of 180 days to 360 days, re-performed the regression analyses, and detected any changes in statistical associations. We used the Statistical Package for Social Sciences version 15 (SPSS, Chicago, IL, USA) for all data analysis. All $P$-values $<0.05$ were regarded as statistically significant.

\section{RESULTS}

\section{Patient characteristics}

From 9398 eligible patients, with an average age of 63.5 years (s.d. 2.5), $67.0 \%$ were female (Table 1). Fee payers were $73.0 \%$ and $94.2 \%$ visited GOPC. A total of $51.7 \%$ lived in the most urbanized district. The majority were new patients $(63.7 \%)$ and had no concomitant comorbidities, apart from uncomplicated hypertension. Patients who continued their medications had significantly more comorbidites (22.2\% of continuers had at least one comorbidity vs. $13.7 \%$ among discontinuers). Among the follow-up visitors, an average of 1.8 visits before antihypertensive prescription was reported. Most of the prescriptions were issued in the calendar years 2004 and 2005.

\section{Thiazide discontinuers and switchers}

The crude cumulative incidences of thiazide discontinuation and switching were 12.5 and $10.8 \%$, respectively. There was a significant 
Table 1 Patient characteristics $(N=9398)$

\begin{tabular}{|c|c|c|}
\hline & No. & $\%$ \\
\hline \multicolumn{3}{|l|}{ Age (years) } \\
\hline$<50$ & 1453 & 15.5 \\
\hline $50-59$ & 2404 & 25.6 \\
\hline $60-69$ & 2267 & 24.1 \\
\hline$\geqslant 70$ & 3274 & 34.8 \\
\hline \multicolumn{3}{|l|}{ Gender } \\
\hline Male & 3102 & 33.0 \\
\hline Female & 6296 & 67.0 \\
\hline \multicolumn{3}{|l|}{ Payment status } \\
\hline Fee waivers & 2536 & 27.0 \\
\hline Fee payers & 6862 & 73.0 \\
\hline \multicolumn{3}{|l|}{ Service type } \\
\hline GOPC & 8850 & 94.2 \\
\hline FMSC & 493 & 5.2 \\
\hline Staff clinic & 55 & 0.6 \\
\hline \multicolumn{3}{|c|}{ District of residence } \\
\hline Shatin & 4859 & 51.7 \\
\hline Taipo & 1660 & 17.7 \\
\hline North & 2238 & 23.8 \\
\hline Others & 641 & 6.8 \\
\hline \multicolumn{3}{|l|}{ Visit type } \\
\hline New & 5990 & 63.7 \\
\hline Old & 3408 & 36.3 \\
\hline \multicolumn{3}{|l|}{ Comorbidities } \\
\hline 0 & 7413 & 78.9 \\
\hline 1 & 1770 & 18.8 \\
\hline$\geqslant 2$ & 215 & 2.3 \\
\hline \multicolumn{3}{|c|}{ Calendar years of prescription } \\
\hline 2004 & 5166 & 55.0 \\
\hline 2005 & 2224 & 23.7 \\
\hline 2006 & 1407 & 15.0 \\
\hline 2007 & 601 & 6.4 \\
\hline
\end{tabular}

Abbreviations: FMSC, Family Medicine Specialist Clinic; GOPC, General Outpatient Clinic. All the percentages are across columns.

difference in the age distribution between discontinuers and continuers $(P<0.001)$, and similarly between switchers and non-switchers $(P=0.001)$ (Table 2). All others stayed on therapy for an average of 46.9 days (s.d. 29.8) between the first and second visit. The average time to switch among the switchers was 93.8 days (s.d. 174.0), whereas the average time to discontinue among the discontinuers was 379.9 days (s.d. 220.0). Higher proportions of discontinuers were male ( 37.7 vs. $32.3 \%, P<0.001)$, attended FMSC (7.0 vs. 5.0\%, $P=0.013$ ), lived in more urbanized districts (55.0 vs. $51.2 \%, P<0.001)$ and were new visitors $(79.1$ vs. $61.5 \%, P<0.001)$. More discontinuers than continuers had no comorbidities (86.3 vs. $77.8 \%, P<0.001)$.

These observations were similar when switchers were compared with non-switchers, with an exception that more switchers lived in rural districts (30.7 vs. $23.0 \%$ ) and the number of comorbidites was similar between the two groups (Table 2).
Factors associated with thiazide discontinuation and switching From multivariate regression analyses, male patients were significantly more likely to discontinue $(\mathrm{AOR}=1.23,95 \% \mathrm{CI} 1.07-1.40, P=0.003$ ) and switch $(\mathrm{AOR}=1.29,95 \% \mathrm{CI} 1.12-1.48, P<0.001)$ their thiazide medications. When compared with patients aged $<50$ years, patients aged $50-69$ years, but not those aged $\geqslant 70$ years, were less likely to discontinue $(50-59$ years; $\mathrm{AOR}=0.74,95 \%$ CI $0.61-0.90, P=0.002$; 60-69 years; AOR $0.57,95 \%$ CI $0.46-0.70, P<0.001)$. Similarly, patients aged $60-69$ years $(\mathrm{AOR}=0.79,95 \%$ CI $0.65-0.98, P=0.028)$ and $\geqslant 70$ years (AOR $0.70,95 \%$ CI $0.57-0.85, P<0.001$ ) were less likely to switch their thiazide prescriptions than those aged $<50$ years (Tables 3 and 4).

The significant associations of age, gender and the type of visit remained similarly significant, when 360 days were used as the time frame instead.

\section{DISCUSSION}

This study showed that among 9398 ethnic Chinese patients, $12.5 \%$ discontinued and $10.8 \%$ switched their thiazide prescriptions within 180 days of the date of the first prescription. Individuals aged less than 50 years, male patients and new visitors were significantly more likely to discontinue or switch their prescriptions, and this finding also holds true within a time frame of 360 days.

From our recent study, ${ }^{11}$ users of $\beta$-blockers were most likely to have their drugs discontinued $(20.8 \%)$, followed by angiotensin converting enzyme inhibitors (14.0\%), thiazide diuretics $(12.5 \%)$ and calcium channel blocker (9.7\%). Discontinuation of prescriptions without replacement by another agent could be due to patient default in subsequent clinic consultations arranged for medication refill. It could also be attributed to medication non-adherence, for example, when patients take the drugs half often as prescribed and attend the clinic for medication refill, when twice the period of average drugs supplied has elapsed. Alternatively, switching of therapy could be better explained by intolerable side effects induced by thiazide diuretics. We have previously shown that advanced age, male gender and thiazide users were significantly associated with hyponatremia ${ }^{21}$ and older or male patients were significantly more likely to present with some aspects of dyslipidemia. ${ }^{22}$ It is well recognized that elderly patients are more sensitive to sodium and showed greater response to diuretics than younger subjects. ${ }^{23}$ Younger patients were more likely to discontinue or switch their medications. This might be due to the fact that the majority of patients aged $<50$ years were still at work. Their busier working schedules, as compared with older patients who were retired, could lead to poorer medication taking behavior and lower commitment to regular clinic attendance. Alternatively, it has been suggested by the Health Belief Model that patients who believed they were sicker, more likely among the elderly than the young, might adhere better to medical treatment. ${ }^{24}$ As Carter $^{25}$ highlighted, recent studies have reported that older subjects ${ }^{24,26-28}$ and women ${ }^{26,29}$ were more likely to adhere to medication regimens, yet the findings were inconclusive. The reasons underlying these observations remained unknown. Moreover, fee-waivers were found to have a higher likelihood of medication discontinuation. From current literature, low socioeconomic status has been identified as a potential barrier to medication adherence. ${ }^{25}$ Proposed reasons include lower educational levels, poorer knowledge of prescribed medications and negative beliefs about hypertension and its treatment among the economically underprivileged. $^{25}$

New visitors were found to have significantly higher rates of discontinuation or switching. A higher proportion of them might be thiazide-naive or newly diagnosed as having hypertension. 
Table 2 Characteristics of thiazide discontinuers and switchers $(\boldsymbol{N}=9398)$

\begin{tabular}{|c|c|c|c|c|c|c|c|c|c|c|}
\hline & \multicolumn{2}{|c|}{ Discontinuers $(\mathrm{n}=1179)$} & \multicolumn{2}{|c|}{ Continuers $(\mathrm{n}=8219)$} & \multirow[b]{2}{*}{$\mathrm{P}$} & \multicolumn{2}{|c|}{ Switchers $(\mathrm{n}=1015)$} & \multicolumn{2}{|c|}{ Non-switchers $(\mathrm{n}=8383)$} & \multirow[b]{2}{*}{$\mathrm{P}$} \\
\hline & No. & $\%$ & No. & $\%$ & & No. & $\%$ & No. & $\%$ & \\
\hline \multicolumn{11}{|l|}{ Age (years) } \\
\hline$<50$ & 236 & 20.0 & 1217 & 14.8 & $<0.001$ & 193 & 19.0 & 1260 & 15.0 & 0.001 \\
\hline $50-59$ & 300 & 25.4 & 2104 & 25.6 & & 270 & 26.6 & 2134 & 25.5 & \\
\hline $60-69$ & 217 & 18.4 & 2050 & 24.9 & & 245 & 24.1 & 2022 & 24.1 & \\
\hline$\geqslant 70$ & 426 & 36.1 & 2848 & 34.7 & & 307 & 30.2 & 2967 & 35.4 & \\
\hline \multicolumn{11}{|l|}{ Gender } \\
\hline Male & 444 & 37.7 & 2658 & 32.3 & $<0.001$ & 400 & 39.4 & 2702 & 32.2 & $<0.001$ \\
\hline Female & 735 & 62.3 & 5561 & 67.7 & & 615 & 60.6 & 5681 & 67.8 & \\
\hline \multicolumn{11}{|l|}{ Payment status } \\
\hline Fee waivers & 358 & 30.4 & 2178 & 26.5 & 0.005 & 291 & 28.7 & 2245 & 26.8 & 0.200 \\
\hline Fee payers & 821 & 69.6 & 6041 & 73.5 & & 724 & 71.3 & 6138 & 73.2 & \\
\hline \multicolumn{11}{|l|}{ Service type } \\
\hline GOPC & 1088 & 92.3 & 7762 & 94.4 & 0.013 & 948 & 93.4 & 7902 & 94.3 & 0.512 \\
\hline FMSC & 82 & 7.0 & 411 & 5.0 & & 61 & 6.0 & 432 & 5.2 & \\
\hline Staff clinic & 9 & 0.8 & 46 & 0.6 & & 6 & 0.6 & 49 & 0.6 & \\
\hline \multicolumn{11}{|c|}{ District of residence } \\
\hline Shatin & 649 & 55.0 & 4210 & 51.2 & $<0.001$ & 485 & 47.8 & 4374 & 52.2 & $<0.001$ \\
\hline Taipo & 148 & 12.6 & 1512 & 18.4 & & 139 & 13.7 & 1521 & 18.1 & \\
\hline North & 286 & 24.3 & 1952 & 23.7 & & 312 & 30.7 & 1926 & 23.0 & \\
\hline Others & 96 & 8.1 & 545 & 6.6 & & 79 & 7.8 & 562 & 6.7 & \\
\hline \multicolumn{11}{|l|}{ Visit type } \\
\hline New & 933 & 79.1 & 5057 & 61.5 & $<0.001$ & 775 & 76.4 & 5215 & 62.2 & $<0.001$ \\
\hline Old & 246 & 20.9 & 3162 & 38.5 & & 240 & 23.6 & 3168 & 37.8 & \\
\hline \multicolumn{11}{|l|}{ Comorbidities } \\
\hline 0 & 1017 & 86.3 & 6396 & 77.8 & $<0.001$ & 813 & 80.1 & 6600 & 78.7 & 0.547 \\
\hline 1 & 145 & 12.3 & 1625 & 19.8 & & 182 & 17.9 & 1588 & 18.9 & \\
\hline$\geqslant 2$ & 17 & 1.4 & 198 & 2.4 & & 20 & 2.0 & 195 & 2.3 & \\
\hline \multicolumn{11}{|c|}{ Calendar years of prescription } \\
\hline 2004 & 344 & 29.2 & 4822 & 58.7 & $<0.001$ & 433 & 42.7 & 4733 & 56.5 & $<0.001$ \\
\hline 2005 & 384 & 32.6 & 1840 & 22.4 & & 303 & 29.9 & 1921 & 22.9 & \\
\hline 2006 & 269 & 22.8 & 1138 & 13.8 & & 212 & 20.9 & 1195 & 14.3 & \\
\hline 2007 & 182 & 15.4 & 419 & 5.1 & & 67 & 6.6 & 534 & 6.4 & \\
\hline
\end{tabular}

Abbreviations: FMSC, Family Medicine Specialist Clinic; GOPC, General Outpatient Clinic.

All the percentages were across columns.

Follow-up visitors were a selected group of patients having received the same medications at least once before their medication was refilled. Therefore, they were less likely to experience medication side effects. This observation was further echoed by studies showing that newly diagnosed hypertensive patients had much lower persistence rates. ${ }^{25,27,30}$ Some have suggested that this could be due to negative beliefs about management of hypertension, as well as inaccurate knowledge and perception about medications among the new visitors. $^{24}$

This is the first study, which identified the factors associated with thiazide discontinuation and switching among ethnic Chinese patients. The major strength of this study is the relatively large sample size and the comprehensive electronic database. The validity of the findings was further enhanced because of the good dispensing and information keeping practices. Several limitations should however be addressed. First, we have included Chinese patients living in one region of Hong Kong only, although the profiles of age and income were similar to the whole population of Hong Kong. These findings could not necessarily be generalizable to the broader population of hypertensive subjects and might be limited to Chinese patients. Patients who were already and newly prescribed thiazide diuretics were both included and the former group is not an inception cohort. Furthermore, the outcomes of this study were health-service oriented without information on patient adherence to follow-up, and the exact reasons of discontinuation and switching could not be evaluated, as the clinical database did not consist of these variables in this retrospective cohort. For instance, erectile dysfunction is a relatively frequent adverse effect of thiazide diuretics ${ }^{31}$ and we did not observe any entry of this medical condition as ICPC codes in our computerized system. In addition, there could be important data regarding the 
Table 3 Factors associated with discontinuation of thiazide $(N=9398)$

\begin{tabular}{|c|c|c|c|c|}
\hline & No. & $\%$ & Adjusted odds ratios $(95 \% \mathrm{Cl})$ & $\mathrm{P}$ \\
\hline \multicolumn{5}{|l|}{ Age (years) } \\
\hline$<50$ & 236 & 16.2 & 1.00 (reference) & \\
\hline $50-59$ & 300 & 12.5 & $0.74(0.61-0.90)$ & 0.002 \\
\hline $60-69$ & 217 & 10.5 & $0.57(0.46-0.70)$ & $<0.001$ \\
\hline$\geqslant 70$ & 426 & 13.0 & $0.88(0.73-1.06)$ & 0.174 \\
\hline \multicolumn{5}{|l|}{ Gender } \\
\hline Female & 735 & 11.7 & 1.00 (reference) & \\
\hline Male & 444 & 14.3 & $1.23(1.07-1.40)$ & 0.003 \\
\hline \multicolumn{5}{|c|}{ Payment status } \\
\hline Fee waivers & 358 & 14.1 & 1.00 (reference) & \\
\hline Fee payers & 821 & 12.0 & $0.85(0.74-0.98)$ & 0.027 \\
\hline \multicolumn{5}{|l|}{ Service type } \\
\hline GOPC & 1088 & 12.3 & 1.00 (reference) & \\
\hline FMSC & 82 & 16.6 & $1.94(1.48-2.54)$ & $<0.001$ \\
\hline Staff clinic & 9 & 16.4 & $1.00(0.47-2.12)$ & 0.998 \\
\hline \multicolumn{5}{|c|}{ District of residence } \\
\hline Shatin & 649 & 13.4 & 1.00 (reference) & \\
\hline Taipo & 148 & 8.9 & $0.72(0.59-0.87)$ & 0.001 \\
\hline North & 286 & 12.8 & $0.94(0.80-1.10)$ & 0.418 \\
\hline Others & 96 & 15.0 & $1.15(0.90-1.47)$ & 0.256 \\
\hline \multicolumn{5}{|l|}{ Visit type } \\
\hline New & 933 & 15.6 & 1.00 (reference) & \\
\hline Old & 246 & 7.2 & $0.55(0.47-0.65)$ & $<0.001$ \\
\hline \multicolumn{5}{|l|}{ Comorbidities } \\
\hline 0 & 1017 & 13.7 & 1.00 (reference) & \\
\hline 1 & 145 & 8.2 & $0.67(0.55-0.81)$ & $<0.001$ \\
\hline$\geqslant 2$ & 17 & 7.9 & $0.69(0.41-1.16)$ & 0.164 \\
\hline
\end{tabular}

methods of classification of hypertension, which have not been addressed. Finally, we captured shorter-term outcomes only and there were limitations related to the clinical database like the absence of confounding variables, for instance blood pressure levels, stage of hypertension, presence of coronary heart diseases or congestive heart failure, use of multiple other medications and beliefs about antihypertensive pharmacotherapy.

The most important implication of this study is the need for exploring and closer monitoring of the medication-taking behavior among younger men who were new attendees of consultations that prescribed a thiazide diuretic. This could be in the form of medication counseling services, refill reminders and adherence aids. ${ }^{24}$ It is important that facilitators of good patient adherence are implemented among these patient groups who were prescribed thaizide diuretics. Not preventing patient-initiated medication discontinuation or in delaying switches might lead to adverse clinical outcomes, including suboptimal blood pressure control, increased complications, hospitalizations and costs. ${ }^{29}$ We suggest the drug adherenceimproving strategies recommended by the American Heart Association be considered especially for these patients in routine clinical care. $^{32,33}$
Table 4 Factors associated with switching of thiazide ( $N=9398)$

\begin{tabular}{|c|c|c|c|c|}
\hline & No. & $\%$ & Adjusted odds ratios $(95 \% \mathrm{Cl}$ ) & $\mathrm{P}$ \\
\hline \multicolumn{5}{|l|}{ Age (years) } \\
\hline$<50$ & 193 & 13.3 & 1.00 (reference) & \\
\hline $50-59$ & 270 & 11.2 & $0.85(0.70-1.04)$ & 0.112 \\
\hline $60-69$ & 245 & 10.8 & $0.79(0.65-0.98)$ & 0.028 \\
\hline$\geqslant 70$ & 307 & 10.7 & $0.70(0.57-0.85)$ & $<0.001$ \\
\hline \multicolumn{5}{|l|}{ Gender } \\
\hline Female & 615 & 9.8 & 1.00 (reference) & \\
\hline Male & 400 & 12.9 & $1.29(1.12-1.48)$ & $<0.001$ \\
\hline \multicolumn{5}{|l|}{ Payment status } \\
\hline Fee waivers & 291 & 11.5 & 1.00 (reference) & \\
\hline Fee payers & 724 & 10.6 & $0.94(0.81-1.09)$ & 0.418 \\
\hline \multicolumn{5}{|l|}{ Service type } \\
\hline GOPC & 948 & 10.7 & 1.00 (reference) & \\
\hline FMSC & 61 & 12.4 & $1.60(1.20-2.15)$ & 0.002 \\
\hline Staff clinic & 6 & 10.9 & $0.78(0.32-1.85)$ & 0.567 \\
\hline \multicolumn{5}{|c|}{ District of residence } \\
\hline Shatin & 485 & 10.0 & 1.00 (reference) & \\
\hline Taipo & 139 & 8.4 & $0.92(0.75-1.12)$ & 0.405 \\
\hline North & 312 & 13.9 & $1.51(1.30-1.77)$ & $<0.001$ \\
\hline Others & 79 & 12.3 & $1.27(0.98-1.64)$ & 0.073 \\
\hline \multicolumn{5}{|l|}{ Visit type } \\
\hline New & 775 & 12.9 & 1.00 (reference) & \\
\hline Old & 240 & 7.0 & $0.57(0.48-0.67)$ & $<0.001$ \\
\hline \multicolumn{5}{|l|}{ Comorbidities } \\
\hline 0 & 813 & 11.0 & 1.00 (reference) & \\
\hline 1 & 182 & 10.3 & $1.06(0.89-1.27)$ & 0.522 \\
\hline$\geqslant 2$ & 20 & 9.3 & $0.95(0.59-1.54)$ & 0.848 \\
\hline
\end{tabular}

Abbreviations: FMSC, Family Medicine Specialist Clinic; GOPC, General Out-patient Clinic. $\%$, represents the percentages of patients with drugs switched. $P<0.05$ were highlighted in bold.

In summary, physicians should pay greater attention when they prescribe thiazide diuretics to the younger, male patients who were new visitors. Future research should evaluate the reasons of discontinuation and switching among these high-risk groups. The associations between discontinuation and switching on blood pressure control and cardiovascular outcomes should also be explored.

\section{CONFLICT OF INTEREST}

The authors declare no conflict of interest.

\section{ACKNOWLEDGEMENTS}

There is no funding for this study. We thank the Hospital Authority and the primary care research group of the School of Public Health, Chinese University of Hong Kong for their expert input.

1 National Collaborating Centre for Chronic Conditions. Hypertension: Management in Adults in Primary Care: Pharmacological Update. Royal College of Physicians: London, 2006.

2 Graham I, Atar D, Borch-Johnsen K, Boysen G, Burell G, Cifkova R, Dallongeville J, De Backer G, Ebrahim S, Gjelsvik B, Herrmann-Lingen C, Hoes A, Humphries S, Knapton M, Perk J, Priori SG, Pyorala K, Reiner Z, Ruilope L, Sans-Menendez S, 
Scholte op Reimer W, Weissberg P, Wood D, Yarnell J, Zamorano JL, Walma E, Fitzgerald T, Cooney MT, Dudina A, European Society of Cardiology (ESC) Committee for Practice Guidelines (CPG). European guidelines on cardiovascular disease prevention in clinical practice: executive summary: Fourth Joint Task Force of the European Society of Cardiology and Other Societies on Cardiovascular Disease Prevention in Clinical Practice (Constituted by representatives of nine societies and by invited experts). Eur Heart J 2007; 28: 2375-2414.

3 Whitworth JA, World Health Organization, International Society of Hypertension Writing Group. 2003 World Health Organization (WHO)/International Society of Hypertension (ISH) statement on management of hypertension. J Hypertens 2003; 21: 1983-1992.

4 Chobanian AV, Bakris GL, Black HR, Cushman WC, Green LA, Izzo Jr JL, Jones DW, Materson BJ, Oparil S, Wright Jr JT, Roccella EJ, National Heart, Lung, and Blood Institute Joint National Committee on Prevention, Detection, Evaluation, and Treatment of High Blood Pressure. National High Blood Pressure Education Program Coordinating Committee. The seventh report of the Joint National Committee on Prevention, Detection, Evaluation, and Treatment of High Blood Pressure: the JNC-7 report. JAMA 2003; 289: 2560-2572.

5 ALLHAT Collaborative Research Group. Major outcomes in high-risk hypertensive patients randomized to angiotensin-converting enzyme inhibitor or calcium channel blocker versus diuretic: the Antihypertensive and Lipid-Lowering Treatment to Prevent Heart Attack Trial (ALLHAT). JAMA 2002; 288: 2981-2997.

6 Tu K, Campbell NRC, Duong-Hua M, McAlister FA. Hypertension management in the elderly has improved: Ontario prescribing trends, 1994 to 2002. Hypertension 2005; 45: 1113-1118.

7 Walley T, Duggan AK, Haycox AR, Niziol CJ. Treatment for newly diagnosed hypertension: patterns of prescribing and antihypertensive effectiveness in the UK. J R Soc Med 2003; 96: 525-531.

$8 \mathrm{Ma} \mathrm{J}$, Lee K-V, Stafford RS. Changes in antihypertensive prescribing during US Outpatient visits for uncomplicated hypertension between 1993 and 2004. Hypertension 2006; 48: 846-852.

9 Wong MC, Jiang JY, Lam AT, Fung H, Griffiths S, Mercer SW. Patterns of antihypertensive prescribing, discontinuation and switching among a Hong Kong Chinese population from over one million prescriptions. J Hum Hypertens 2008; 22: 714-716.

10 Wong MCS. Short- and long-term discontinuation patterns of commonly prescribed antihypertensive drugs among a Chinese population: cohort study. J Hum Hypertens 2008; 22: 435-437.

11 Wong MCS, Jiang JY, Gibbs T, Griffiths S. Factor associated with antihypertensive drug discontinuation among Chinese patients: a cohort study. Am J Hypertens 2009; 22 802-810.

12 Wong MCS, Jiang JY, Griffiths S. Switching of antihypertensive drugs among 93,286 Chinese patients: a cohort study. J Hum Hypertens 2010; 24: 669-677.

13 Wong MCS, Jiang JY, Griffiths S. Factor associated with compliance, discontinuation and switching of calcium channel blockers in 20,156 Chinese patients. Am J Hypertens 2009; 22: 904-910.

14 Wong MCS, Jiang JY, Lam AT, Fung H, Griffiths S, Mercer SW. Health services research in the public healthcare system in Hong Kong: an analysis of over 1 million antihypertensive prescriptions between 2004-2007 as an example of the potential and pitfalls of using routinely collected electronic patient data. BMC Health Services Research 2008; 8: 138.
$15 \mathrm{HA}$ and clinical research-support, output and direction. Available at http:// www.ha.org.hk/ho/research_ethics/msdc_p181.pdf. Accessed on 06 Oct, 2009.

16 Population by census, 2006. Hong Kong Special Administrative Region, China. http://www. bycensus2006.gov.hk/en/index.htm. Accessed September 14, 2009.

17 Burke TA, Sturkenboom MC, Lu S, Wenworth CE, Lin Y, Rhoads GG. Discontinuation of antihypertensive drugs among newly diagnosed hypertensive patients in UK general practice. J Hypertens 2006; 24: 1193-1200.

18 Mazzaglia G, Mantovani LG, Sturkenboom MCJM, Filippi A, Trifirò G, Cricelli C, Brignoli 0 , Caputi AP. Patterns of persistence with antihypertensive medications in newly diagnosed hypertensive patients in Italy: a retrospective cohort study in primary care. J Hypertens 2005; 23: 2093-2100.

19 Katz MH (ed.) Multivariable Analysis: A Practical Guide for Clinicians, 2nd edn. Cambridge University Press: Cambridge, 2006, pp 69.

20 Jiang JY, Wong MCS, Ali MK, Griffiths SM, Mercer SW. Association of antihypertensive monotherapy with serum sodium and potassium levels in Chinese patients. Am J Hypertens 2009; 22: 243-249.

21 Wong MCS, Jiang JY, Ali MK, Fung $\mathrm{H}$, Griffiths S, Mercer SW. Antihypertensive drug class and dyslipidemia: risk association among Chinese patients with uncomplicated hypertension. J Hum Hypertens 2008; 22: 648-651.

22 Weinberger MH. Salt sensitivity of blood pressure in humans. Hypertension 1996; 27. 481-490.

23 Billups SJ, Malone DC, Carter BL. The relationship between drug therapy noncompliance and patient characteristics, health-related quality of life, and health care costs. Pharmacotherapy 2000; 20: 941-949.

24 Carter BL. Adherence, quality of life, cost effectiveness, and the role of the pharmacist. In: Lip GYH, Hall JE (eds). Comprehensive Hypertension. Mosby Elsevier: Philadelphia, 2007, pp 1119-1127.

25 Caro JJ, Salas M, Speckman JL, Raggio G, Jackson JD. Persistence with treatment for hypertension in actual practice. CMAJ 1999; 160: 31-37.

26 Degli Esposti L, Degli Esposti E, Valpiani G, Di Martino M, Saragoni S, Buda S, Baio G, Capone A, Sturani A. A retrospective, population-based analysis of persistence with antihypertensive drug therapy in primary care practice in Italy. Clin Ther 2002; 24: 1347-1357.

27 Vaur L, Vaisse B, Genes N, Elkik F, Legrand C, Poggi L. Use of electronic pill boxes to assess risk of poor treatment compliance: results of a large-scale trial. Am J Hypertens 1999; 12: 374-380.

28 Flack JM, Novikov SV, Ferrario CM. Benefits of adherence to antihypertensive drug therapy. Eur Heart J 1996; 17SA: 16-20.

29 Degli Esposti E, Sturani A, Di Martino M, Falasca P, Novi MV, Baio G, Buda S, Volpe M. Long-term persistence with antihypertensive drugs in new patients. $J$ Hum Hypertens 2002; 16: 439-444.

30 Mickley $\mathrm{H}$. Incidence and treatment of sexual dysfunction in heart disease. Ugeskrift for Laeger 2002; 164: 4760-4764.

31 Miller NH, Hill M, Kottke T, Ockene IS. The multilevel compliance challenge: recommendations for a call to action. A statement for healthcare professionals. Circulation 1997; 95: 1085-1090.

32 Schroeder K, Fahey T, Ebrahim S. How can we improve adherence to blood pressurelowering medication in ambulatory care? Systematic review of randomized controlled

trials. Arch Intern Med 2004; 164: 722-732. 